\title{
Evaluation and Optimization Study on a Hybrid EOR Technique Named as Chemical-Alternating-Foam Floods
}

\author{
Xingguang $\mathrm{Xu}^{*}$ and Ali Saeedi \\ Department of Petroleum Engineering, Curtin University, 6152 Perth - Australia \\ e-mail: xuxingguang123@126.com \\ * Corresponding author
}

\begin{abstract}
This work presents a novel Enhanced Oil Recovery (EOR) method called ChemicalAlternating-Foam (CAF) floods in order to overcome the drawbacks of the conventional foam flooding such as insufficient amount of in-situ foams, severe foam collapse and surfactant retention. The first part of this research focused on the comparison of conventional foam floods and CAF floods both of which had the same amount of gas and chemicals. It showed that: (1) CAF floods possessed the much greater Residual Resistance Factor (RRF) at elevated temperature; (2) the accumulative oil recovery of the CAF floods was 10\%-15\% higher than that of the conventional foam flooding. After 1.8 Pore Volume (PV) injection, the oil recovery reached the plateau for both methods; (3) CAF floods yielded the most amount of incremental oil at the $98 \%$ water cut (water content in the effluent), while the continuous foam floods achieved the best performance at $60 \%$ water cut. The second part of this work determined the optimal foam quality (gas/liquid ratio or the volume percent gas within foam), chemical/foam slug size ratio, cycle number and injection sequence for the CAF floods. It was found that the CAF was endowed with the peak performance if the foam quality, chemicalfoam slug size ratio, cycle number was fixed at 80\%, 1:1 and 3 respectively with the chemical slug being introduced ahead of the foam slug. Through systematic and thorough research, the proposed hybrid process has been approved to be a viable and effective method significantly strengthening the conventional foam flooding.
\end{abstract}

Résumé - Évaluation et optimisation d'une technique de RAH hybride appelée Injection de Mousse Chimique Alternative - Cet article présente une nouvelle méthode de Récupération Assistée des Hydrocarbures (RAH). Cette méthode, appelée injection de Mousse Chimique Alternative (MCA), permet de s'affranchir des inconvénients de l'injection de mousse conventionnelle, tels qu'une quantité insuffisante de mousse in situ, l'instabilité importante de la mousse ainsi qu'une rétention de tensioactif. La première partie de ces travaux de recherche s'est focalisée sur la comparaison entre l'injection de mousse conventionnelle et l'injection de MCA comportant, dans les deux cas, la même quantité de gaz et de produits chimiques. Il a été démontré que : (1) les injections de MCA présentaient le meilleur Facteur de Résistance Résiduel (FRR) à une température élevée ; (2) la récupération d’hydrocarbures cumulée par injections de MCA était de 10 à $15 \%$ supérieure à celle de l'injection de mousse conventionnelle. Après une injection de 1,8 fois le Volume Poreux (VP), la récupération d'hydrocarbures a atteint un plafond pour les deux méthodes ; (3) les injections de MCA ont donné la plus grande quantité de pétrole avec une teneur en eau de $98 \%$ (teneur en eau dans l'effluent), pendant que l'injection de mousse atteignait les meilleures performances à $60 \%$ de teneur en eau. La seconde 
partie de ce travail a consisté à déterminer la qualité optimale de la mousse (rapport gaz/liquide ou volume de gaz en pourcentage dans la mousse), le rapport mousse/produit chimique de l'écoulement, le nombre de cycles et la séquence d'injection pour les injections MCA. Il s'est avéré que la MCA présente des performances optimales si la qualité de la mousse, le rapport mousse/produit chimique de l'écoulement, le nombre de cycles étaient fixés à $80 \%, 1: 1$ et 3 respectivement, le flux de produit chimique étant introduit avant le flux de mousse. Grâce à une recherche systématique et minutieuse, le processus hybride proposé a été validé comme étant une méthode viable et efficace présentant une amélioration par rapport à l'injection de mousse conventionnelle.

\section{INTRODUCTION}

Foams, a unique type of colloidal dispersion, usually refer to a system in which a gas phase (internal phase) is dispersed in a continuous liquid phase (external phase) (Gauglitz et al., 2002). As a result of its distinct flowing and rheological properties, the foam has been widely used as drilling fluid, fracturing fluid and acidizing fluid in the petroleum industry over the past decades (Bernadiner et al., 1992; Harris, 1995; Ozbayoglu et al., 2002). Nonetheless, perhaps its most attracting application is to offer the best hope for mobility control in gas flooding suffering from poor volumetric sweep efficiency due to the displacement front instability and early breakthrough caused by the undesirable gravity segregation and viscous fingering (Casteel and Djabbarah, 1988; Chen et al., 2005; Friedmann et al., 1991; Prigiobbe et al., 2016). This Enhanced Oil Recovery (EOR) technique is defined as the foam flooding. Through introducing foams into the oil reservoir, no matter the foam is pre-generated or not, the gas relative permeability will be markedly reduced. Meanwhile, the high permeability zone is preferably blocked by the foam, significantly alleviating the reservoir heterogeneity. Thus this EOR process can take place in the low permeability zone which otherwise would be bypassed in a conventional gas flooding. A great number of laboratory and numerical investigations have been performed to approve the effectiveness of the foam flooding worldwide in recent years (Ebrahimi et al., 2016; Haugen et al., 2014; Jian et al., 2012; Thorat and Bruining, 2016; Wang et al., 2011).

Needless to say, foam flooding is not without its drawbacks as an oil displacement technique. The major concern is the foam durability (Schramm and Novosad, 1990). It is well accepted that the foam decays either through lamella collapse or bubble coalescence. The former is mainly attributed to the film thinning caused by the gravity drainage over time, thus the lamella is not robust enough to hold the backbone of the foam system. In the case of bubble coalescence, several bubbles approach so closely that they fuse together to yield a single bubble. The foam stability may be influenced by a couple of factors: capillary suction, electric double-layer repulsion, dispersion force attraction and so on (Alvarez et al., 2001; Khatib et al., 1988). In real oil reservoirs, high salinity, elevated temperature and the presence of crude oil will all negatively affect the performance of foam (Jonas et al., 1990). Another disadvantage that may hinder the successful application of the foam flooding is the surfactant loss due to adsorption onto the reservoir rock and chemical reaction with the minerals (Falcone et al., 1982; Gogoi, 2011). Consequently, the amount of the surfactant that involve in the foam generation and regeneration in porous rocks will be greatly reduced, resulting in worse displacement outcome than anticipated. Although the surfactant retention would be relieved somehow at relatively high reservoir temperature, this cannot be considered as a trivial problem in the field operation (Fjelde et al., 2009).

A number of attempts have been reported to make the best use of the efficiency of the foam flooding. Le et al. (2008) dissolved the surfactant into the dense $\mathrm{CO}_{2}$ phase instead of the brine and found its overall oil recovery was evidently higher than that of surfactant-alternating-gas injection or continuous gas injection; Kutay and Schramm (2004) reported the encouraging performance of the PolymerEnhanced Foam (PEF) and pointed out its foam durability could be considerably improved by increasing the bulk phase viscosity and thus reducing the rate of liquid drainage; Worthen et al. (2013) developed a novel approach stabilizing the foam with nanoparticles such as silicon and they considered this method as a promising alternative to the conventional surfactant-stabilized foam; Majidaie et al. (2012) investigated the performance of the Chemically Enhanced Water Alternating Gas (CWAG) flooding by using a commercial chemical flood simulator; Tay et al. (2015) and other researchers introduced and validated the effectiveness of the so called adsorption inhibitor which was capable of significantly mitigating the surfactant loss in reservoirs. Nevertheless, each of these proposed techniques can only tackle one problem of the foam flooding (either the foam stability or surfactant retention), little work has been conducted managing to address both issues. Moreover, some solutions stated above such as nanoparticles-stabilized 
foam and $\mathrm{CO}_{2}$-soluable surfactant are considered to be costly for the field operation, disabling their application in the reservoir scale.

This research presents a new EOR technique which combines Surfactant/Polymer (SP) with the conventional $\mathrm{CO}_{2}$ foam, named as Chemicals-Alternating-Foam (CAF) flooding. The selection of $\mathrm{CO}_{2}$ as the gas phase in the foam slug is considered to be in favour of the greenhouse effect alleviation. In this proposed technique, $\mathrm{CO}_{2}$ foam and SP solution are alternatively introduced into the core sample the same as the Water-Alternating-Gas (WAG) process. On the one hand, the foams will be greatly stabilized due to the presence of the chemical slug; on the other hand, the surfactant loss in the foam flooding can be supplemented to a great extent by the surfactant contained in the chemical slug. Consequently, the two chief issues of the foam flooding would be lifted by the introduction of the surfactant/ cosolvent/polymer slug. The first part of this paper compares the displacement performance of the conventional $\mathrm{CO}_{2}$ foam flooding with that of the CAF flooding. It is noteworthy that the two investigated EOR methods employ the same amounts of $\mathrm{CO}_{2}$ as well as chemicals in total. In the second part, optimization study is conducted to define the operation parameters those will lead to a satisfying EOR outcome. Through systematic assessment, it is believed that CAF flooding might be a promising alternative for the conventional foam flooding.

\section{EXPERIMENTAL SECTION}

\subsection{Materials}

Chemical formula: The sodium Alpha Olefin Sulfonate (AOS $\mathrm{C}_{14-16}$ ) with $35 \%$ active matter is supplied by Stepan Chemical Co. (USA) and used as the foaming agent. Cosolvent N70K-T is able to boost the lamella strength in the foaming system and purchased from Solvay Chemicals Inc. (USA). The product information is tabulated in Table 1. AVS, a ter-polymer product with a molecular weight of $10 \times 10^{6} \mathrm{~g} / \mathrm{mol}$ and hydrolysis degree of $22 \%$, is provided by the Research Institute of Petroleum Exploration \& Development (RIPED, China) as a thickener in the chemical solution. The molecular structure of the AVS is illustrated in Figure 1. The chemical formulation (surfactant/cosolvent/ polymer) in this study is determined as 0.5 wt. $\%$ AOS +0.15 wt. $\%$ AVS +0.5 wt. $\%$ N70K-T unless otherwise specified. Detailed description of this chemical formula can be found somewhere else (Xu et al., 2017).

Brine: Synthetic brine A with the salinity of $5000 \mathrm{ppm}$ $(\mathrm{NaCl})$ is employed for the chemical solution preparation. Brine B with the salinity of $20000 \mathrm{ppm}(\mathrm{NaCl})$ is used in the core flooding experiments.
TABLE 1

Properties of the cosolvent N70K-T.

\begin{tabular}{c|c}
\hline Property & Result \\
\hline Appearance & Clear gel \\
\hline $\mathrm{pH}$ & $7.0-8.0$ aqueous solution \\
\hline Freezing point & $<-2{ }^{\circ} \mathrm{C}$ \\
\hline Boiling point & $104{ }^{\circ} \mathrm{C}$ \\
\hline Density & $1.03 \mathrm{~g} / \mathrm{cm}^{3}$ \\
\hline Dynamic viscosity @ $25{ }^{\circ} \mathrm{C}$ & $50 \mathrm{mPa} \mathrm{s}$ \\
\hline Water solubility @ $25{ }^{\circ} \mathrm{C}$ & $55 \mathrm{~g} / \mathrm{L}$ \\
\hline Active & $68 \%$ \\
\hline
\end{tabular}

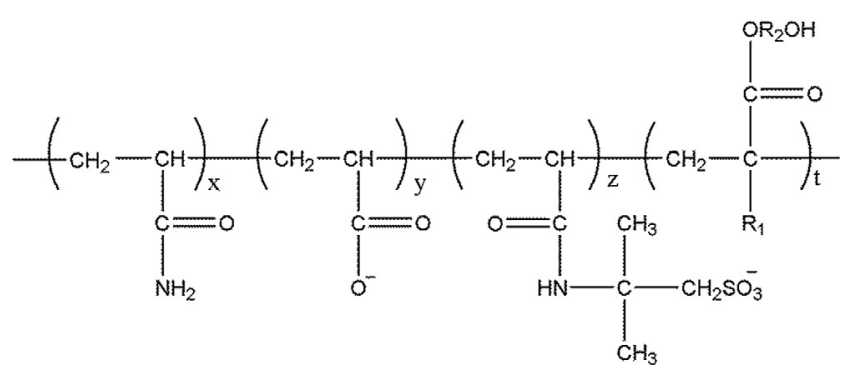

Figure 1

The molecular structure of the polymer AVS.

Core plug: Berea samples with length around $6.9 \mathrm{~cm}$ and diameters of $3.8 \mathrm{~cm}$ are cut from quarried sandstone blocks (Ohio, USA) and are used as supplied. The porosity and permeability of these plugs are about $18 \%$ and $400 \mathrm{mD}$ respectively. Their chemical compositions are determined by the X-Ray powder Diffraction (XRD) technique and are presented in Figure 2. Scanning Electron Microscope (SEM) image of the sample powder is given in Figure 3.

Crude oil: Oil sample is sourced from an oil reservoir located on North West Shelf of Western Australia and its properties are listed in Table 2. It is noted that the oil sample is filtered before any use.

\subsection{Experimental Procedure}

\subsubsection{Residual Resistance Factor Evaluation}

Residual Resistance Factor (RRF), which is the ratio of brine relative permeability before and after the EOR treatment, shows the ability of the EOR technique to reduce the permeability in porous medium. If brines flow at the same 


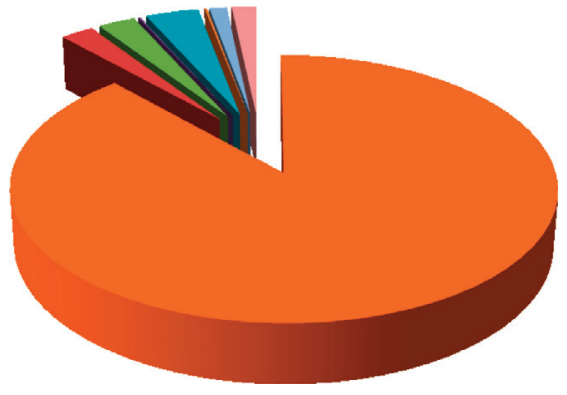

- $83.15 \%$ SiO2

- $2.15 \% \mathrm{CaO}$

- $2.44 \% \mathrm{CO} 2$

- $0.09 \% \mathrm{Na} 2 \mathrm{O}$

- $3.45 \% \mathrm{Al} 2 \mathrm{O} 3$

$0.14 \% \mathrm{H} 2 \mathrm{O}$

$0.12 \% \mathrm{MgO}$

- $1.59 \% \mathrm{~K} 2 \mathrm{O}$

Figure 2

$\mathrm{XRD}$ analysis of the investigated rock samples.

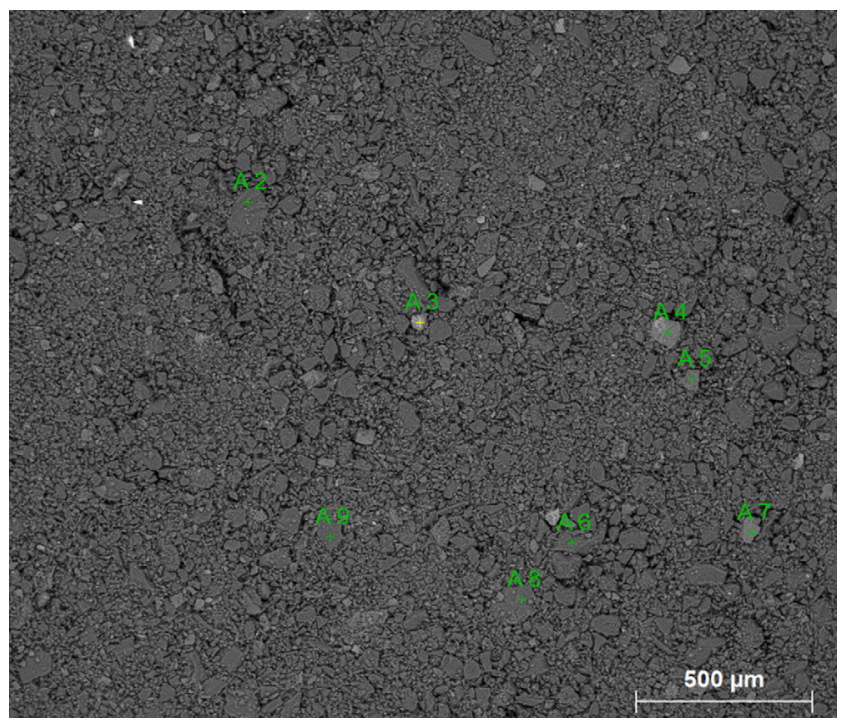

Figure 3

SEM image of the investigated rock samples.

rate before and after the EOR treatment, RRF can be calculated by the following equation:

$$
\mathrm{RRF}=\frac{K_{w}}{K_{f}}=\frac{\Delta P_{2}}{\Delta P_{1}}
$$

where $K_{w}$ is the relative permeability of brine before chemical flooding and $K_{f}$ is the relative permeability of the brine after chemical flooding; $\Delta P_{1}$ and $\Delta P_{2}$ are the pressure drops of the brine flow before and after the treatment respectively.

The experimental setup is illustrated in Figure 4. Brine B was injected into the core plug at $1.0 \mathrm{~mL} / \mathrm{min}$ until steady $\Delta P_{1}$ was reached. Then $2.0 \mathrm{PV}$ of supercritical $\mathrm{CO}_{2}$ and 2.0 PV of AOS/AVS/N70K-T solution (SP solution)
TABLE 2

Properties of the crude oil.

\begin{tabular}{c|c|c}
\hline Test & Unit & Result \\
\hline Density $@ 15{ }^{\circ} \mathrm{C}$ & $\mathrm{Kg} / \mathrm{L}$ & 0.9428 \\
\hline API gravity & ${ }^{\circ} \mathrm{API}$ & 18.5 \\
\hline Asphaltenes & $\%$ mass & 0.14 \\
\hline Arsenic & $\mathrm{mg} / \mathrm{kg}$ & 2.3 \\
\hline $\begin{array}{c}\text { Kinematic viscosity } \\
\text { @ } 40{ }^{\circ} \mathrm{C}\end{array}$ & $\mathrm{cSt}$ & 37.26 \\
\hline Sulphur-total & $\% \mathrm{mass}$ & 0.14 \\
\hline Total acid number & $\mathrm{mg} \mathrm{KOH} / \mathrm{g}$ & 0.50 \\
\hline Water content & $\%$ volume & 0.150 \\
\hline
\end{tabular}

were fed into the core plug in two ways, as illustrated in Figure 5:

(a) The foam was produced with the assistance of a foam generator into which the supercritical $\mathrm{CO}_{2}$ and SP solution were injected. Therefore, $4.0 \mathrm{PV}$ of foam could be introduced into the core plug continuously.

(b) The foam was created the same way. Through adjusting the plug valve mounted upstream the $\mathrm{CO}_{2}$ gas cylinder, 3.0 PV of foam and 1.0 PV of SP solution were injected alternatively in two cycles (each cycle contains 1.5 PV of foam and 0.5 PV of SP solution).

Afterward the injection was shifted to the brine B flowing at $1.0 \mathrm{~mL} / \mathrm{min}$ and was ceased at the point where $\Delta P_{2}$ could be measured. The back pressure was maintained at $2000 \mathrm{psi}$ unless otherwise stated.

\subsubsection{Foam Apparent Viscosity}

Foam effectiveness is a strong function of foam apparent viscosity. On the basis of single-phase Darcy law, the apparent foam viscosity can be expressed as:

$$
\mu_{\text {foam }, \text { app }}=\frac{k A \Delta p}{\left(q_{\mathrm{g}}+q_{1}\right) L}
$$

where $k$ is the effective permeability of the core plug, $A$ is the cross section to foam flow, $q_{\mathrm{g}}$ and $q_{1}$ are the volumetric flow rate of $\mathrm{CO}_{2}$ gas and foaming solution respectively, $\Delta p / L$ is the pressure gradient across full length of the core plug. Chemical solution or SP solution (5.0 PV) was fed into the core plug to satisfy the surfactant adsorption before the injection of $\mathrm{CO}_{2}$ foam which was produced through the foam generator. The differential pressure at different times during experiment was monitored and recorded by pressure transducers (KELLER, Switzerland) mounted at the inflow and 


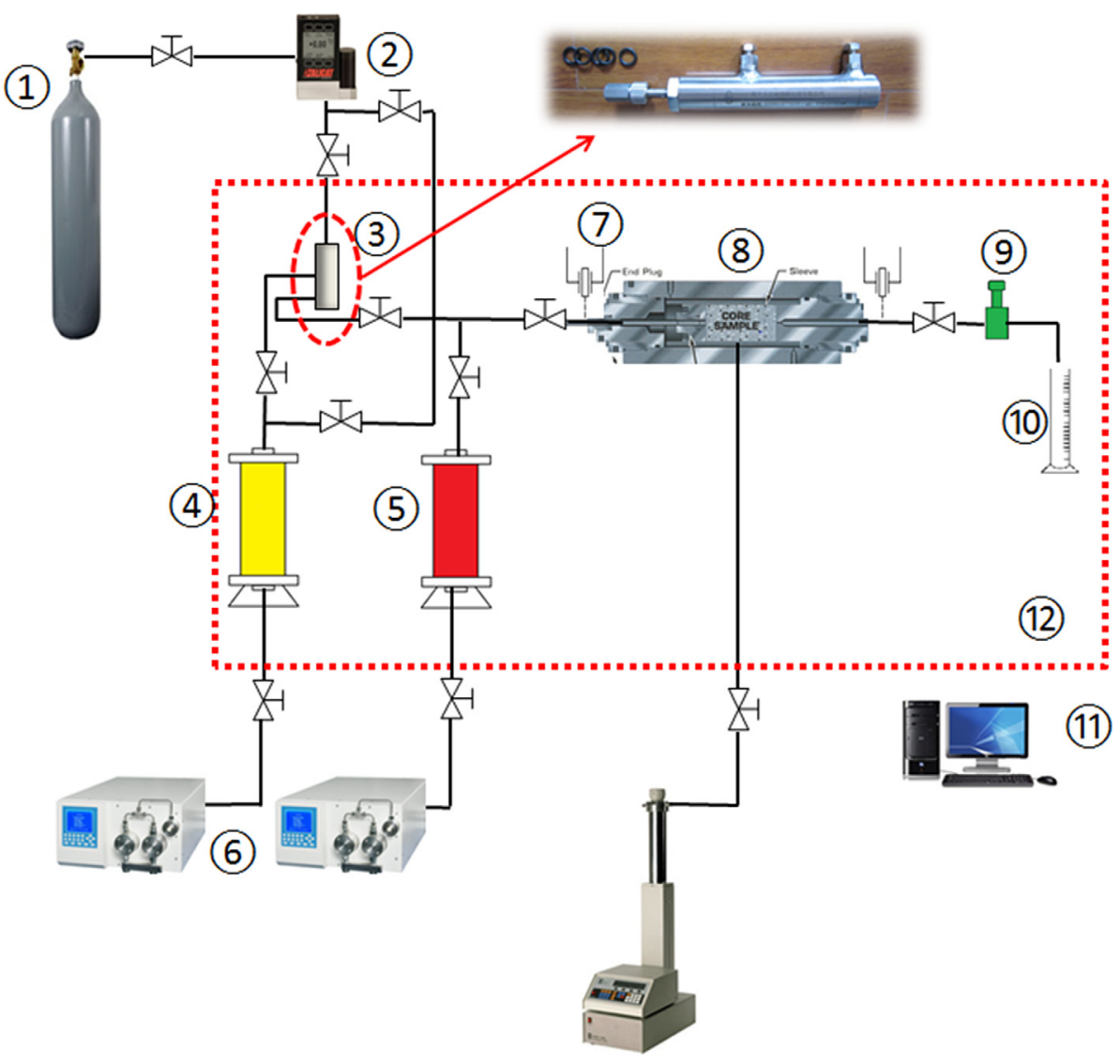

Figure 4

The experimental setup for the foam and CAF floods evaluation. $1-\mathrm{CO}_{2}$ tank, 2 - Gas mass flow control system, 3 - Foam generator, 4 - Chemical solution, 5 - Sythetic brine/crude oil, 6 - Injection pump, 7 - Pressure transducer, 8 - Core holder, 9 - Back pressure regulator, 10 - Graduated cylinder, 11 - Data acquisition system, 12 - Heating system.

outflow end of the core holder. Gas/liquid ratio (foam quality) would not be altered until steady state flow was achieved which was indicated by negligible fluctuation $(<5.0 \mathrm{psi})$ of pressure drop. The temperature and pressure were kept at $50{ }^{\circ} \mathrm{C}$ and 2000 psi unless otherwise stated.

\subsubsection{Oil Displacement Experiment}

The schematic of the oil displacement experiment is also shown in Figure 4. The back pressure was constant at 2000 psi during core flood process. Detailed experimental steps are as follows:

1. The sandstone core plug was dried out at $65{ }^{\circ} \mathrm{C}$ for four days and its porosity and gas permeability were determined by an Automated Permeameter-Porodimeter (Coretest systems, Inc., USA) before it was loaded horizontally into the core holder. Then overburden pressure up to 4000 psi was applied to the core plug which, afterward, was vacuumed for at least $12 \mathrm{~h}$ to remove the air from the core holder.

2. The core plug was then fully saturated with the brine B flowing at $0.5 \mathrm{~mL} / \mathrm{min}$ until steady-state flow was achieved. Accordingly, its liquid permeability could be calculated by applying the single-phase Darcy's law.

3. Crude oil was pumped into the core holder at $0.3 \mathrm{~mL} / \mathrm{min}$ until the water cut reaches $1 \%$ to attain the residual water saturation; afterwards, the core plug is aged for $24 \mathrm{~h}$.

4. Water floods with brine $\mathrm{B}$ at $0.5 \mathrm{~mL} / \mathrm{min}$ was conducted, enabling the residual oil saturation to be established, which was indicated by the $99 \%$ water cut.

5. Given amount of supercritical $\mathrm{CO}_{2}$ and chemicals are injected into the core plug by either approach stated above, which was then followed by the chase waterfloods at $0.5 \mathrm{~mL} / \mathrm{min}$ until $99 \%$ water cut was reached. 


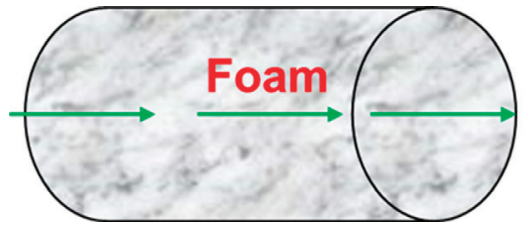

a)

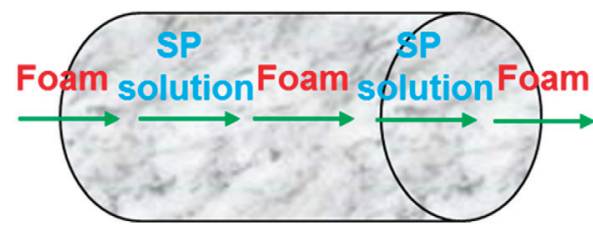

b)

Figure 5

Illustration of the continuous foam flooding a) and CAF flooding b).

TABLE 3

Summary of the RRF assessment.

\begin{tabular}{c|c|c|c|c|c|c}
\hline Run No. & 1 & 2 & 3 & 4 & 5 & 6 \\
\hline Method & $\mathrm{a}$ & $\mathrm{b}$ & $\mathrm{a}$ & $\mathrm{b}$ & $\mathrm{a}$ & $\mathrm{b}$ \\
\hline Permeability (mD) & $394.4 \pm 2.5$ & $389.6 \pm 5.1$ & $406.6 \pm 6.0$ & $399.1 \pm 4.2$ & $394.7 \pm 4.7$ & $392.3 \pm 5.4$ \\
\hline Pressure (psi) & 2000 & 2000 & 2000 & 2000 & 2000 & 80 \\
\hline Temperature ( $\left.{ }^{\circ} \mathrm{C}\right)$ & 20 & 20 & 50 & 50 & 2.2000 \\
\hline $\mathrm{P}_{1}$ (psi) & $2.38 \pm 0.04$ & $2.51 \pm 0.03$ & $2.24 \pm 0.06$ & $2.39 \pm 0.04$ & 0.02 & $2.35 \pm 0.05$ \\
\hline $\mathrm{P}_{2}$ (psi) & $14.91 \pm 0.03$ & $20.45 \pm 0.06$ & $10.28 \pm 0.06$ & $18.12 \pm 0.03$ & $5.86 \pm 0.05$ & $15.89 \pm 0.04$ \\
\hline RRF & $6.26 \pm 0.04$ & $8.15 \pm 0.05$ & $4.59 \pm 0.06$ & $7.58 \pm 0.04$ & $2.67 \pm 0.04$ & $6.76 \pm 0.05$ \\
\hline
\end{tabular}

\section{RESULTS AND DISCUSSION}

As stated in the introduction section, two aspects of work are presented in this paper: the first part compares the flowing performance of the conventional foam flooding with that of the proposed CAF flooding in the porous medium. Same amount of supercritical $\mathrm{CO}_{2}$ and chemicals (AOS/AVS/ N70K-T) are used in the two EOR approaches. The second part is the optimization study of the CAF flooding on the purpose of maximizing the displacement efficiency of this new EOR technique.

\subsection{Investigation on the Flow Behaviour of the $\mathrm{CO}_{2}$ Foam Flooding and $\mathrm{CO}_{2} \mathrm{CAF}$ Flooding}

\subsubsection{Effect of the Temperature on the Residual Resistance Factor (RRF)}

2.0 PV of supercritical $\mathrm{CO}_{2}$ and 2.0 PV of chemicals are introduced into the porous medium in two ways. The assessment results are summarized in Table 3 . The RRF of the two injection strategies at varying temperatures is illustrated in Figure 6. It was found that the temperature imposed negative impact on the RRF for both injection scenarios. On the one hand, with the temperature rising, the chemical adsorption onto the rock would be lifted somehow, enabling more foam to reside in the porous medium and thus contributing to the permeability reduction after the chase brine was initiated. On the other hand, the elevated temperature could greatly accelerate the foam decay, even if the foam was stabilized by the additives. Furthermore, the polymer thermal degradation became a lot more pronounced at high temperature. Consequently, the relative permeability of the chase brine could not be modified as well as that in low temperature. Another noticeable phenomenon was that CAF flooding was endowed with greater capability to reduce the brine permeability compared to the continuous foam flooding, and this trend became evident with the increasing temperature, as illustrated by the dash lines in Figure 6. The RRF differences between them validated the effectiveness of the CAF flooding in the investigated temperature range. Taking into account that higher RRF brought in greater flow resistance to the brine, therefore, the breakthrough of chase brine after CAF flooding could be greatly deferred and more spaces in the porous rocks would be swept.

\subsubsection{Effect of the Amount of Supercritical $\mathrm{CO}_{2}$ and Chemicals on the Displacement Performance}

In this subsection, five sets (ten runs) of oil displacement experiments were carried out at $50{ }^{\circ} \mathrm{C}$ and 2000 psi with the total amount of supercritical $\mathrm{CO}_{2}$ and chemicals ranging 


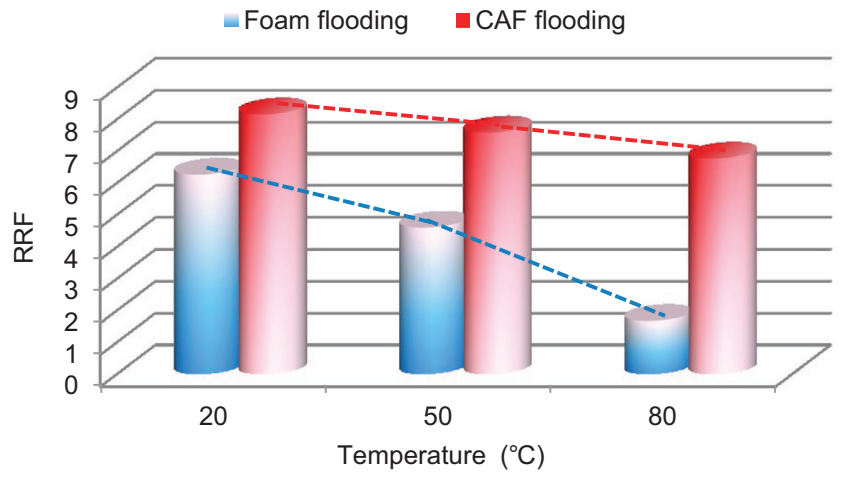

Figure 6

Effect of the temperature on the RRF of foam and CAF flooding.

from $0.4 \mathrm{PV}$ to $2.0 \mathrm{PV}$. The volume ratio of the $\mathrm{CO}_{2}$ and chemicals was fixed at 3:1 in each run irrespective of the injection strategy. In the CAF flooding process, the foam slug and chemical slug were alternatively pumped in three cycles. In each run, firstly the secondary water flooding was initiated, with the oil recovery and oil saturation around $40 \%$ and $23 \%$ respectively. Afterwards, given amount of supercritical $\mathrm{CO}_{2}$ and chemicals were introduced into the core plug either in the mode of continuous foam flooding or CAF flooding. Subsequently, the run was ended up with the chase water flood. The corresponding results were shown in Figure 7. Obviously, the introduced $\mathrm{CO}_{2}$ and chemicals enabled the oil production to improve significantly irrespective of the injected mode and amount. Accordingly, the oil saturation after tertiary recovery was remarkably lower than that after the secondary water flood. In general, more injected PV led to more incremental oil production and it reached the plateau at a specific injected PV. Moreover, it was found the EOR capacity differences between the two injection approaches were evident: the overall oil recovery of the CAF flooding was $10 \%-15 \%$ higher compared to that of the conventional foam flooding with the same amount of gas and chemicals been injected. The chief cause was the variation of the foam stability. In CAF flooding, the foam was protected and stabilized by the chemical slug. Furthermore, the surfactant loss could be supplemented by the subsequent chemical solution. Last but not the least, the addition of the SP solution was capable of improving the sweep efficiency. All of these mechanisms gave rise to the oil production directly or indirectly. It also could be observed that the oil recovery barely increased if the total injection amount was larger than 1.8 PV for both injection approaches. Therefore, the optimal injection amount was chosen as 1.8 PV for the economical consideration.

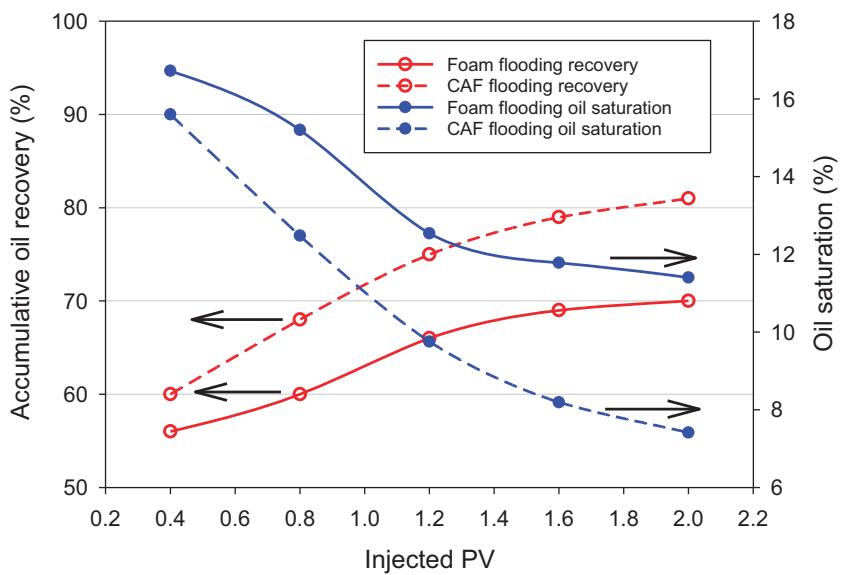

Figure 7

Effect of the total injected PV on the accumulative oil recovery and oil saturation.

\subsubsection{Effect of the Injection Timing of the $\mathrm{CO}_{2}$ and Chemicals on the Accumulative Oil Recovery}

In order to evaluate the impact of the injection timing on the displacement performance of the continuous foam flooding and the CAF flooding, six runs of core floods were performed at $50{ }^{\circ} \mathrm{C}$ and 2000 psi with 1.35 PV of supercritical $\mathrm{CO}_{2}$ and $0.45 \mathrm{PV}$ of the chemicals being injected in either mode. In the CAF flooding process, the foam slug and chemical slug were alternatively pumped in three cycles. The gas and chemicals were fed into the core plug when the initial water cut was $0 \%$ (i.e. the foam or CAF flooding was used as a secondary recovery method), $60 \%$ (i.e. the water flood was used as a secondary recovery method until the water cut reached $60 \%$, then the foam or CAF flooding was initiated as a tertiary recovery method), or $98 \%$ (i.e. the water flood was used as a secondary recovery method until the residual oil saturation was established and then the foam or CAF flooding was initiated as a tertiary recovery method). Afterwards, a chase brine flood was introduced to finalize the experiment. The experimental results were presented in Table 4 and Figure 8. As could be seen, the total oil recovery was the lowest if the gas and chemicals were injected as a secondary recovery method regardless of the injection mode, which indicated the oil detrimentally affected the foam stability. Yet in the CAF flooding, the chemical slug was injected ahead of the $\mathrm{CO}_{2}$ foam and it could serve as a buffer to protect the foam from breakdown somehow. As for the continuous $\mathrm{CO}_{2}$ foam flooding, more incremental oil was yielded if the gas and chemicals were injected at $60 \%$ water cut compared to the case of the $98 \%$ water cut, as illustrated in Run 3 and 5. This phenomenon demonstrated either high oil saturation or water saturation 
TABLE 4

Summary of the injection timing evaluation.

\begin{tabular}{c|c|c|c|c|c|c}
\hline Run No. & 1 & 2 & 3 & 4 & 5 & 6 \\
\hline Injection mode & $\mathrm{a}$ & $\mathrm{b}$ & $\mathrm{a}$ & $\mathrm{b}$ & $\mathrm{a}$ & $\mathrm{b}$ \\
\hline Injected amount & $1.8 \mathrm{PV}$ & $1.8 \mathrm{PV}$ & $1.8 \mathrm{PV}$ & $1.8 \mathrm{PV}$ & $1.8 \mathrm{PV}$ & \multicolumn{1}{c}{$1.8 \mathrm{PV}$} \\
\hline Initial water cut & 0 & 0 & $60 \%$ & $60 \%$ & $98 \%$ \\
\hline Water flood recovery & $\mathrm{N} / \mathrm{A}$ & $\mathrm{N} / \mathrm{A}$ & $35.3 \pm 0.5 \%$ & $34.2 \pm 0.4 \%$ & $40.2 \pm 0.4 \%$ & $40.8 \pm 0.3 \%$ \\
\hline EOR recovery & $57.6 \pm 0.3 \%$ & $64.7 \pm 0.2 \%$ & $36.0 \pm 0.3 \%$ & $43.5 \pm 0.3 \%$ & $27.3 \pm 0.3 \%$ & $38.4 \pm 0.3 \%$ \\
\hline Total recovery & $57.6 \pm 0.3 \%$ & $64.7 \pm 0.2 \%$ & $71.3 \pm 0.3 \%$ & $77.7 \pm 0.3 \%$ & $67.5 \pm 0.4 \%$ & $79.2 \pm 0.3 \%$ \\
\hline
\end{tabular}

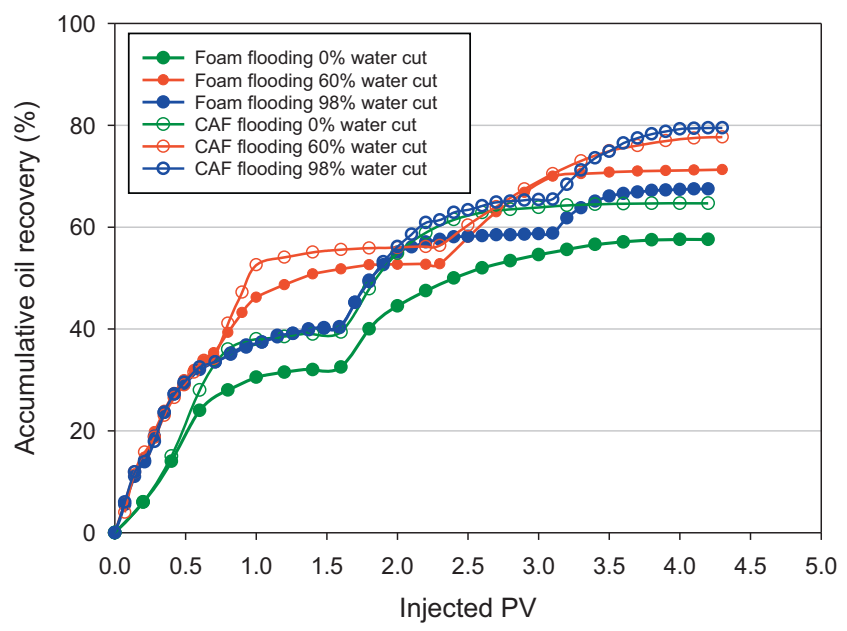

Figure 8

Effect of the injection timing on the accumulative oil recovery.

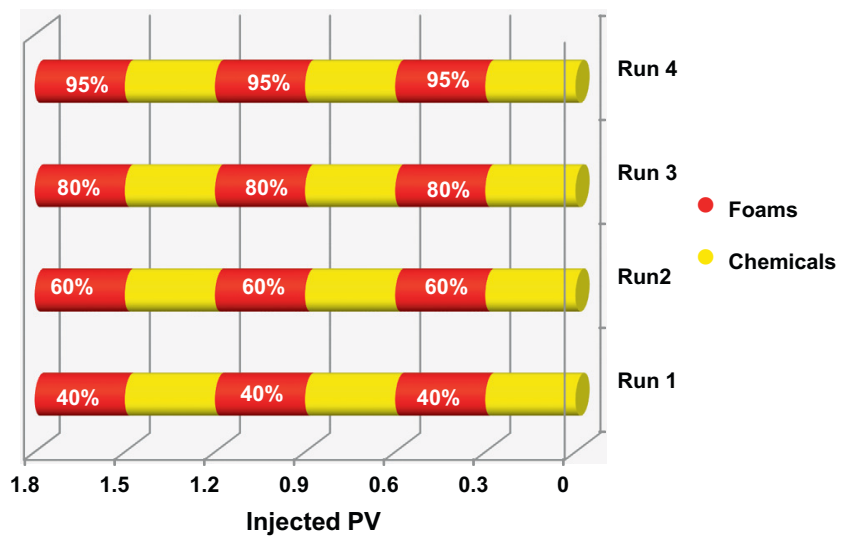

Figure 9

Illustration of the CAF flooding with various foam qualities. could compromise the foam durability for the continuous foam flooding, although it seemed the oil recovery suffered more from high oil saturation. In the case of CAF flooding, the scenario was different: high water cut did not appear to affect the oil displacement. Instead, the cumulative oil recovery at $98 \%$ water cut was a bit greater than that at $60 \%$ water cut, suggesting the performance of the CAF flooding was negatively correlated to the oil saturation. Moreover, irrespective of the water cut in the effluent, the displacement efficiency was strongly dependent on the foam stability, and this might explain why the CAF flooding performed better at identical water cut in terms of the displacement efficiency.

\subsection{Optimization Study of the CAF Flooding}

In this part, a series of optimization studies have been conducted to maximize the displacement efficiency of the proposed CAF flooding in the porous rock. The total amount of the gas and chemicals involved in each experiment was maintained at $1.8 \mathrm{PV}$. The variables such as foam quality, slug size and cycle number were assessed and adjusted to endow the CAF floods with the optimal displacement outcomes. All the core floods were carried out at $50{ }^{\circ} \mathrm{C}$ and 2000 psi unless otherwise specified.

\subsubsection{Effect of the Foam Quality (Gas/Liquid Ratio) in the CAF Flooding on the Displacement Efficiency}

The foam quality, which substantially influences the foam rheological behaviour, is considered to be crucial in the foam flooding as well as the CAF flooding. The foam and the chemical slug were injected into the core plug in three cycles. In each cycle, the slug size of both the foam and the chemical were fixed at $0.3 \mathrm{PV}$. The foam quality ranged from $40 \%$ to $95 \%$ in different runs, as presented in Figure 9. The experimental conditions and corresponding results were demonstrated in Table 5 and Figure 10. With the gas fraction increasing, the amount of produced foam would increase 
TABLE 5

Summary of the investigation on the foam quality of CAF flooding.

\begin{tabular}{c|c|c|c|c}
\hline Run No. & 1 & 2 & 3 & 4 \\
\hline Porosity & $17.12 \pm 0.13 \%$ & $17.05 \pm 0.12 \%$ & $17.24 \pm 0.12 \%$ & $17.13 \pm 0.10 \%$ \\
\hline Permeability & $404.3 \pm 6.4 \mathrm{mD}$ & $399.7 \pm 5.9 \mathrm{mD}$ & $408.7 \pm 6.1 \mathrm{mD}$ & $401.6 \pm 4.8 \mathrm{mD}$ \\
\hline Chemical size in each cycle & $0.3 \mathrm{PV}$ & $0.3 \mathrm{PV}$ & $0.3 \mathrm{PV}$ & $0.3 \mathrm{PV}$ \\
\hline Foam size in each cycle & $0.3 \mathrm{PV}$ & $0.3 \mathrm{PV}$ & $0.3 \mathrm{PV}$ & $0.3 \mathrm{PV}$ \\
\hline Foam quality & $40 \%$ & $60 \%$ & $80 \%$ & 3 \\
\hline Cycle number & 3 & 3 & 3 & $70.6 \pm 0.2 \%$ \\
\hline Initial oil saturation & $71.4 \pm 0.1 \%$ & $70.5 \pm 0.2 \%$ & $40.5 \pm 0.3 \%$ & $31.0 \pm 0.1 \%$ \\
\hline Recovery after water floods & $40.2 \pm 0.2 \%$ & $40.6 \pm 0.2 \%$ & $45.6 \pm 0.3 \%$ & $39.8 \pm 0.2 \%$ \\
\hline Recovery by CAF floods & $20.3 \pm 0.3 \%$ & $37.1 \pm 0.2 \%$ & $77.7 \pm 0.2 \%$ & $25.2 \pm 0.0 .3 \%$ \\
\hline Cumulative oil recovery & $60.5 \pm 0.3 \%$ & & & $65.0 \pm 0.3 \%$ \\
\hline
\end{tabular}

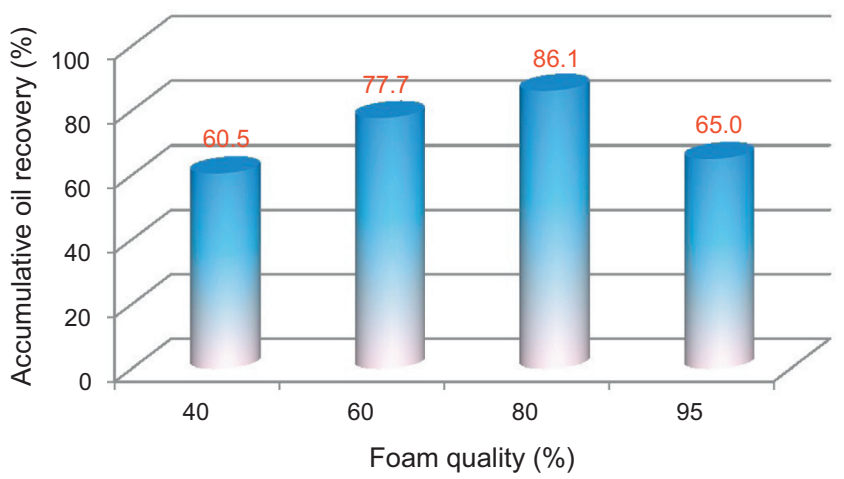

Figure 10

Effect of the foam quality on the accumulative oil recovery.

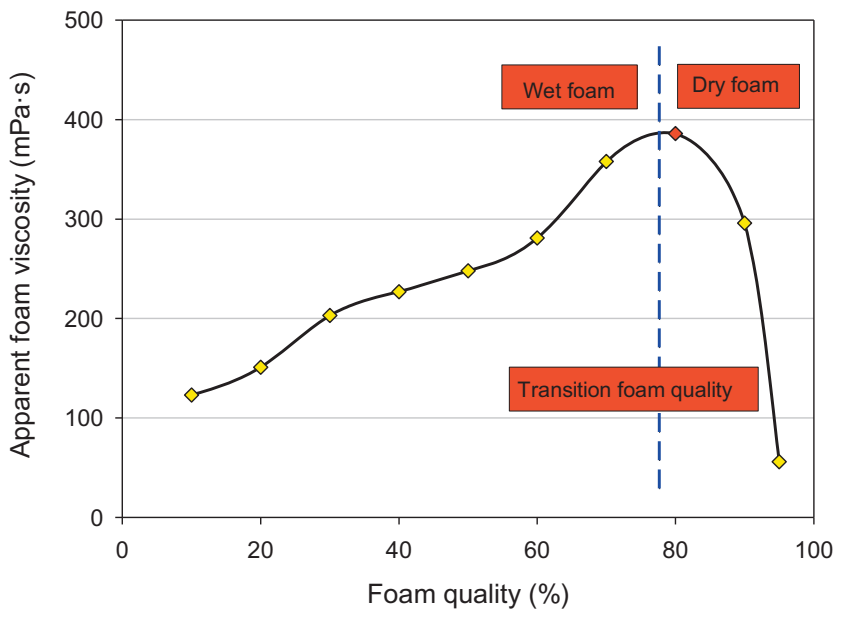

Figure 11

Effect of the foam quality on the apparent viscosity.

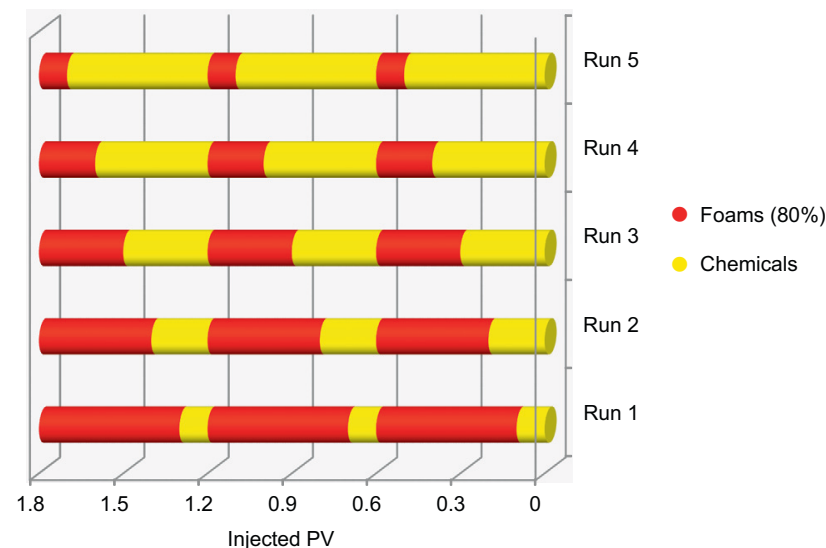

Figure 12

Illustration of the CAF flooding with various foam/chemical slug size ratios.

accordingly, which apparently boosted the overall displacement efficiency. It was noticeable that the tertiary oil recovery decreased once the gas/liquid ratio (foam quality) exceeded a certain value, which might indicate early gas breakthrough had occurred in the foam slug due to the high flowability of the gas phase. Consequently, reliable foams could not be obtained, even if the existence of the $\mathrm{SP}$ solution mitigated this issue to some extent. The recovery variation also could be explained by the varying foam apparent viscosity, as illustrated in Figure 11. The maximum foam apparent viscosity was obtained under a specific foam quality known as the transition foam quality which was roughly $80 \%$ in this case. Neither relative low nor high foam 
TABLE 6

Summary of the investigation on the slug size ratio of CAF flooding.

\begin{tabular}{c|c|c|c|c|c}
\hline Run No. & 1 & 2 & 3 & 4 & 5 \\
\hline Porosity & $17.34 \pm 0.15 \%$ & $17.09 \pm 0.11 \%$ & $17.24 \pm 0.10 \%$ & $17.21 \pm 0.10 \%$ & $17.15 \pm 0.17 \%$ \\
\hline Permeability & $409.6 \pm 7.1 \mathrm{mD}$ & $402.7 \pm 5.2 \mathrm{mD}$ & $408.7 \pm 5.6 \mathrm{mD}$ & $415.6 \pm 5.3 \mathrm{mD}$ & $401.1 \pm 7.8 \mathrm{mD}$ \\
\hline $\begin{array}{c}\text { Chemical size in each } \\
\text { cycle }\end{array}$ & $0.1 \mathrm{PV}$ & $0.2 \mathrm{PV}$ & $0.3 \mathrm{PV}$ & $0.2 \mathrm{PV}$ & $0.5 \mathrm{PV}$ \\
\hline $\begin{array}{c}\text { Foam size in each } \\
\text { cycle }\end{array}$ & $0.5 \mathrm{PV}$ & $0.4 \mathrm{PV}$ & $0.3 \mathrm{PV}$ & $80 \%$ & 3 \\
\hline $\begin{array}{c}\text { Foam quality } \\
\text { Cycle number }\end{array}$ & $80 \%$ & $80 \%$ & $80 \%$ & 3 & $30 \%$ \\
\hline $\begin{array}{c}\text { Initial oil saturation } \\
\text { Recovery after water } \\
\text { floods }\end{array}$ & $39.9 \pm 0.2 \%$ & $69.4 \pm 0.2 \%$ & $70.6 \pm 0.2 \%$ & $69.1 \pm 0.2 \%$ & 3 \\
\hline $\begin{array}{c}\text { Recovery by CAF } \\
\text { floods }\end{array}$ & $32.4 \pm 0.3 \%$ & $35.9 \pm 0.4 \%$ & $40.5 \pm 0.2 \%$ & $39.9 \pm 0.2 \%$ & $40.1 \pm 0.1 \%$ \\
\hline $\begin{array}{c}\text { Cumulative oil } \\
\text { recovery }\end{array}$ & $71.9 \pm 0.3 \%$ & $76.1 \pm 0.3 \%$ & $86.1 \pm 0.3 \%$ & $67.4 \pm 0.3 \%$ & $27.5 \pm 0.3 \%$ \\
\hline
\end{tabular}

quality was capable of producing thick foam remarkable blockage was expected to be achieved around the transition foam quality. Consequently, more incremental oil was recovered compared to other CAF floods with the same amount of gas and chemicals.

\subsubsection{Effect of the Slug Size on the Displacement Efficiency}

In this subsection, core floods were carried out to investigate the dependence of the displacement efficiency on the foam and chemical slug sizes. The foam and the chemical slug were injected into the core plug in three cycles, making the total amount of the foam and chemicals $0.6 \mathrm{PV}$ for each cycle. The foam quality was kept at $80 \%$ for all the core floods, while the sizes of the foam and chemical slug varied in different runs, as presented in Figure 12. The results were summarized in Table 6 and Figure 13. For all the experiments in this subsection, Run 3 was selected as the best injection strategy. The assessment results demonstrated that if the chemical slug and foam slug were injected in the identical volume for each cycle, it would be more beneficial compared to the other scenarios. This phenomenon was primarily attributed to the comprehensive interaction of the foam and chemical slugs. On one hand, if the foam slug size was greater than that of the chemical slug in one cycle (Run 1 and Run 2), the chemical was not capable of offering adequate stabilization and protection for the foam. As a consequence, CAF flooding was very much similar to the conventional foam flooding. On the other hand, if the

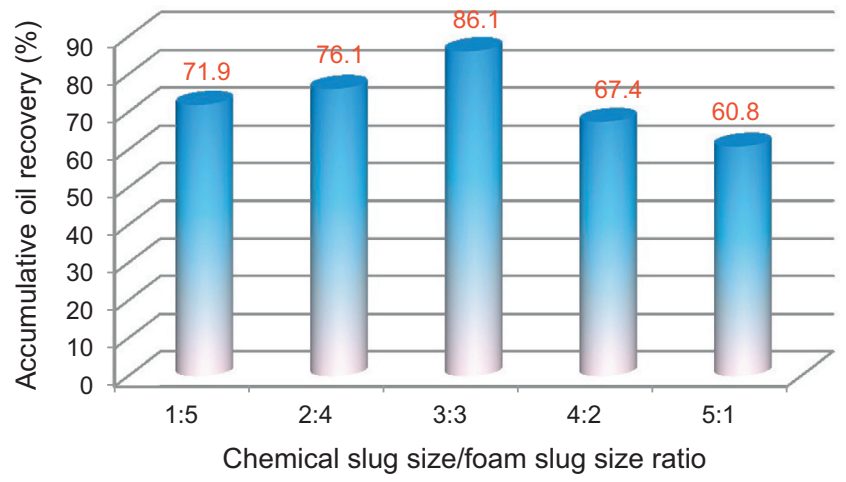

Figure 13

Effect of the slug size ratio on the accumulative oil recovery of the CAF flooding.

amount of the chemical slug surpassed that of the foam slug in one cycle (Run 4 and Run 5), the foam slug was prone to be penetrated by the chemicals, which narrowed the difference between the CAF flooding and chemical (SP) flooding. In both scenarios, the synergism of the foam and chemicals was negatively affected and accordingly the displacement performance of the CAF flooding was badly compromised. Another intriguing feature was the varying recoveries of the cases where the foam slug and chemical slug were not endowed with the same size. It appeared that the cases of more injected foam (Run 1 and Run 2) 


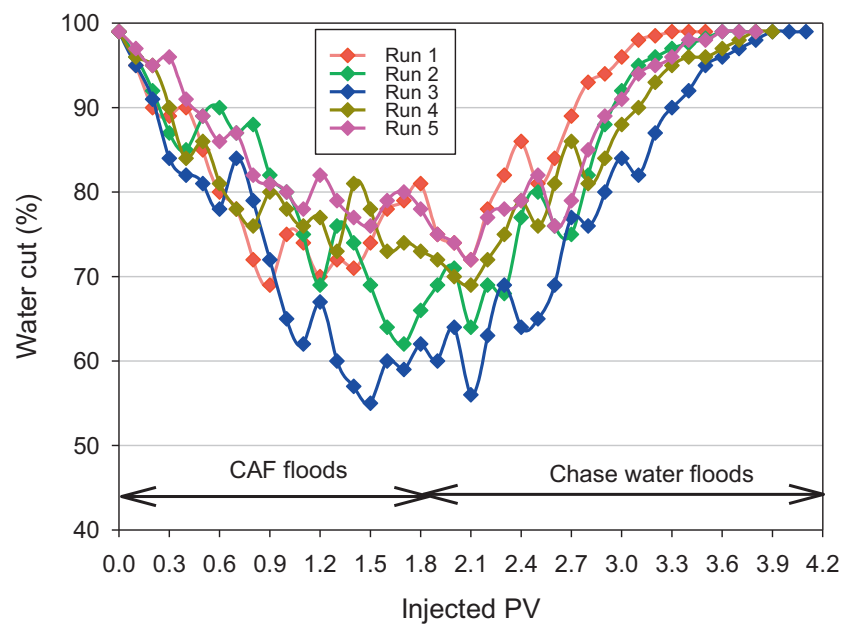

Figure 14

The effect of the slug size ratio on the water cut in the CAF and chase water floods process.

were in favour of the incremental oil production compared to the cases of the more injected chemicals (Run 4 and Run 5). This recovery variation was closely associated with the viscosity difference of the foam and SP in the porous medium. As could be seen in Figure 11, the foam viscosity at transient foam quality reached up to $350 \mathrm{mPa} \mathrm{s}$, but as for the SP solution, the viscosity was far lower than that value at the given temperature and shear rate. Subsequently, more areas could be swept and more incremental oil was yielded by the foam-dominated floods (Run 1 and Run 2). Still, Run 3 with the identical size of the foam slug and chemical slug performed the best among these experiments with various slug size ratios. Its advantage over the others could be validated by Figure 14 which shown the water cut variation in the process of the CAF floods (the water cut reached $99 \%$ after the secondary water floods and then the CAF and chase water floods were conducted). Obviously, the outstanding performance of the Run 3 was to huge extent attributed to its remarkable capability of the water control, especially in the phase of the chase water floods.

\subsubsection{Effect of the Cycle Number on the Displacement Efficiency}

In order to investigate the influence imposed by the cycle number on the displacement efficiency, a set of core floods were conducted. The foam and chemicals were fed into the core plug in various cycle numbers, and the slug size ratio was constant at 1:1 in each cycle, as illustrated in Figure 15. The assessment results were summarized in Table 7 and

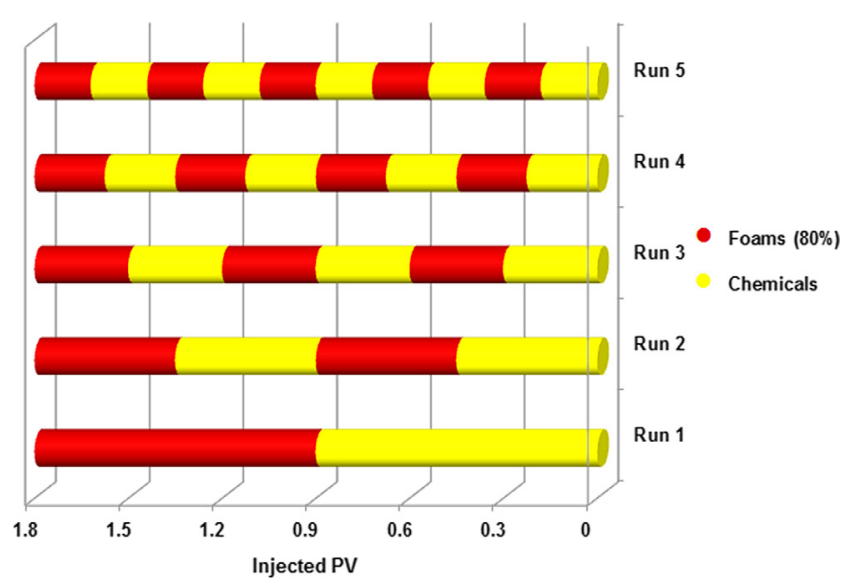

Figure 15

Illustration of the CAF flooding with various cycle numbers.

Figure 16. As expected, the cycle number indeed had huge impact on the behaviour of the CAF flooding. Generally, more incremental oil was produced with the increasing cycle number. The tertiary oil recovery nearly increased by $10 \%$ as the cycle number rose from 1 to 5 . This was attributed to the sufficient interaction between the foams and chemicals as the cycle number increased and slug size declined, which suggested adequate material exchange would take place between the two types of displacement slugs. Consequently, the foam stability was considerably improved via the supplement of the surfactant and polymer provided by the chemical slugs. Theoretically, the CAF flooding would possess the best displacement performance if the cycle number which was close to infinity could be obtained. Nevertheless, as demonstrated in Figure 16, the recovery increase became less noticeable after the cycle number reached 3. That was, the cycle number merely influenced the displacement efficiency of the CAF floods to a tiny extent if the foams and chemicals were injected through more than three cycles. Increasing the cycle number could lead to more operation complexity and more uncertainty but little incremental oil production, therefore, the optimal cycle number was determined as 3 in this study.

\subsubsection{Effect of the Injection Sequence on the Displacement Efficiency}

The last part of the optimization work evaluated the influence of the injection sequence of the foams and chemical slugs on the displacement performance of the CAF flooding. Two runs of the core floods were carried out in this subsection. After the secondary water flooding was finalized, the foam and chemicals slug were injected into the core plug in three cycles with different sequences. In each cycle, $0.3 \mathrm{PV}$ of 
TABLE 7

Summary of the investigation on the cycle number of CAF flooding.

\begin{tabular}{|c|c|c|c|c|c|}
\hline Run No. & 1 & 2 & 3 & 4 & 5 \\
\hline Porosity & $17.15 \pm 0.12 \%$ & $17.06 \pm 0.18 \%$ & $17.24 \pm 0.17 \%$ & $17.17 \pm 0.12 \%$ & $17.09 \pm 0.12 \%$ \\
\hline Permeability & $407.0 \pm 6.4 \mathrm{mD}$ & $401.9 \pm 8.2 \mathrm{mD}$ & $408.7 \pm 7.5 \mathrm{mD}$ & $410.2 \pm 6.2 \mathrm{mD}$ & $408.5 \pm 6.0 \mathrm{mD}$ \\
\hline $\begin{array}{c}\text { Chemical size in each } \\
\text { cycle }\end{array}$ & $0.9 \mathrm{PV}$ & $0.45 \mathrm{PV}$ & $0.3 \mathrm{PV}$ & $0.225 \mathrm{PV}$ & $0.18 \mathrm{PV}$ \\
\hline $\begin{array}{c}\text { Foam size in each } \\
\text { cycle }\end{array}$ & $0.9 \mathrm{PV}$ & $0.45 \mathrm{PV}$ & $0.3 \mathrm{PV}$ & $0.225 \mathrm{PV}$ & $0.18 \mathrm{PV}$ \\
\hline Foam quality & $80 \%$ & $80 \%$ & $80 \%$ & $80 \%$ & $80 \%$ \\
\hline Cycle number & 1 & 2 & 3 & 4 & 5 \\
\hline Initial oil saturation & $69.2 \pm 0.1 \%$ & $69.7 \pm 0.2 \%$ & $70.6 \pm 0.2 \%$ & $70.5 \pm 0.2 \%$ & $69.9 \pm 0.2 \%$ \\
\hline $\begin{array}{c}\text { Recovery after water } \\
\text { floods }\end{array}$ & $40.5 \pm 0.3 \%$ & $39.9 \pm 0.2 \%$ & $40.5 \pm 0.2 \%$ & $40.2 \pm 0.3 \%$ & $40.4 \pm 0.2 \%$ \\
\hline $\begin{array}{c}\text { Recovery by CAF } \\
\text { floods }\end{array}$ & $37.5 \pm 0.3 \%$ & $40.6 \pm 0.3 \%$ & $45.6 \pm 0.4 \%$ & $46.6 \pm 0.2 \%$ & $47.2 \pm 0.2 \%$ \\
\hline $\begin{array}{l}\text { Cumulative oil } \\
\text { recovery }\end{array}$ & $78.0 \pm 0.3 \%$ & $80.5 \pm 0.3 \%$ & $86.1 \pm 0.4 \%$ & $86.8 \pm 0.3 \%$ & $87.6 \pm 0.3 \%$ \\
\hline
\end{tabular}

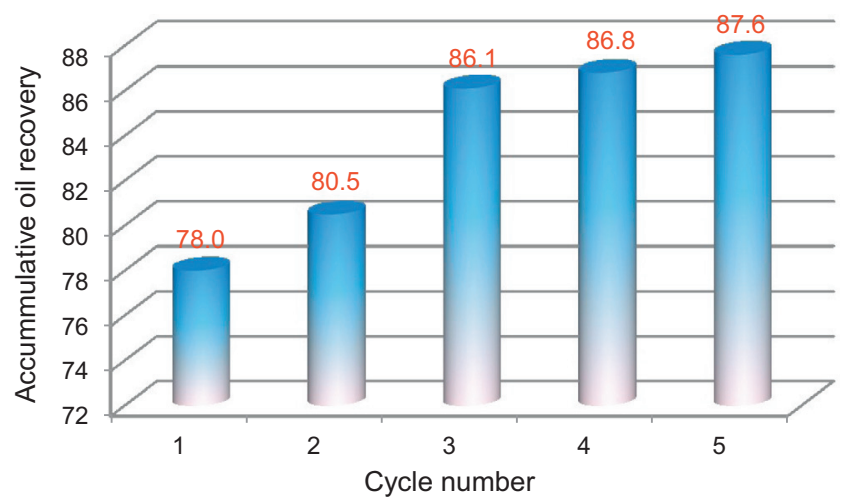

Figure 16

Effect of the cycle number on the accumulative oil recovery of the CAF flooding.

foams and 0.3 PV of chemicals were included, as presented in Figure 17. The results were given in Table 8. Despite the identical foam quality, slug size ratio and cycle number possessed by the two experiments, their displacement efficiency was dependent on the injection sequence of the foam and chemical slug. Better performance could be obtained in Run 1 with the chemicals being injected ahead of the foams, which was verified by its higher oil recovery. The advantage of this injection sequence might be explained in a few aspects: (1) the polymer was capable of modifying the

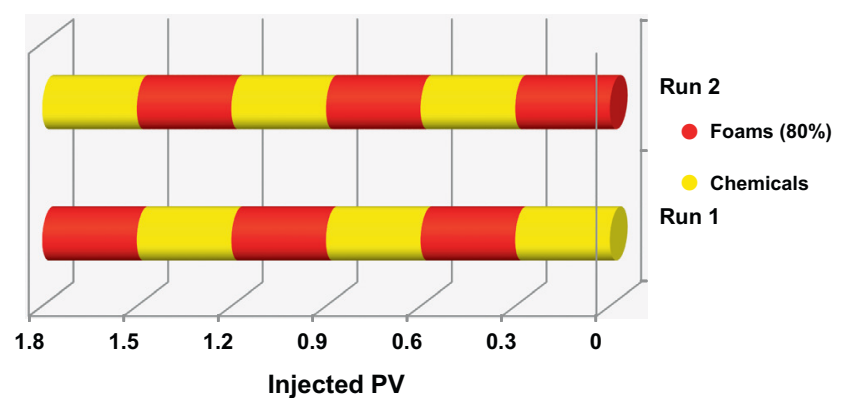

Figure 17

Illustration of the CAF flooding with different injection sequence.

conformance, enabling the subsequent foam floods to sweep more areas; (2) the surfactant served as the sacrificial agent and reduced the foaming agent loss of the foam flooding; (3) the chemicals floods prior to the foam injection decreased the oil saturation in the pore plug, which was favourable for the foam longevity. However, as illustrated in Figure 18, the recovery difference between the two experiments was not quite evident, suggesting the injection sequence was not a strong function of the CAF performance. To sum up, the injection sequence of the foam and chemical did impose impact on the CAF floods, but in a less noticeable manner compared to the other factors investigated above. 
TABLE 8

Summary of the investigation on the injection sequence of CAF flooding.

\begin{tabular}{c|c|c}
\hline Run No. & 1 & 2 \\
\hline Porosity & $17.24 \pm 0.21 \%$ & $17.15 \pm 0.17 \%$ \\
\hline Permeability & $408.7 \pm 7.5 \mathrm{mD}$ & $407.0 \pm 5.6 \mathrm{mD}$ \\
\hline $\begin{array}{c}\text { Chemical size in } \\
\text { each cycle }\end{array}$ & $0.3 \mathrm{PV}$ & $0.3 \mathrm{PV}$ \\
\hline $\begin{array}{c}\text { Foam size in each } \\
\text { cycle }\end{array}$ & $0.3 \mathrm{PV}$ & $0.3 \mathrm{PV}$ \\
\hline Foam quality & $80 \%$ & $80 \%$ \\
\hline $\begin{array}{c}\text { Initial injection slug } \\
\text { Cycle number }\end{array}$ & 3 & $\mathrm{Foam}$ \\
\hline $\begin{array}{c}\text { Initial oil saturation } \\
\text { Recovery after water } \\
\text { floods }\end{array}$ & $70.6 \pm 0.3 \%$ & $70.1 \pm 0.3 \%$ \\
\hline $\begin{array}{c}\text { Recovery by CAF } \\
\text { floods }\end{array}$ & $45.6 \pm 0.3 \%$ & $39.9 \pm 0.3 \%$ \\
\hline $\begin{array}{c}\text { Cumulative oil } \\
\text { recovery }\end{array}$ & $86.1 \pm 0.4 \%$ & $80.4 \pm 0.4 \%$ \\
\hline
\end{tabular}

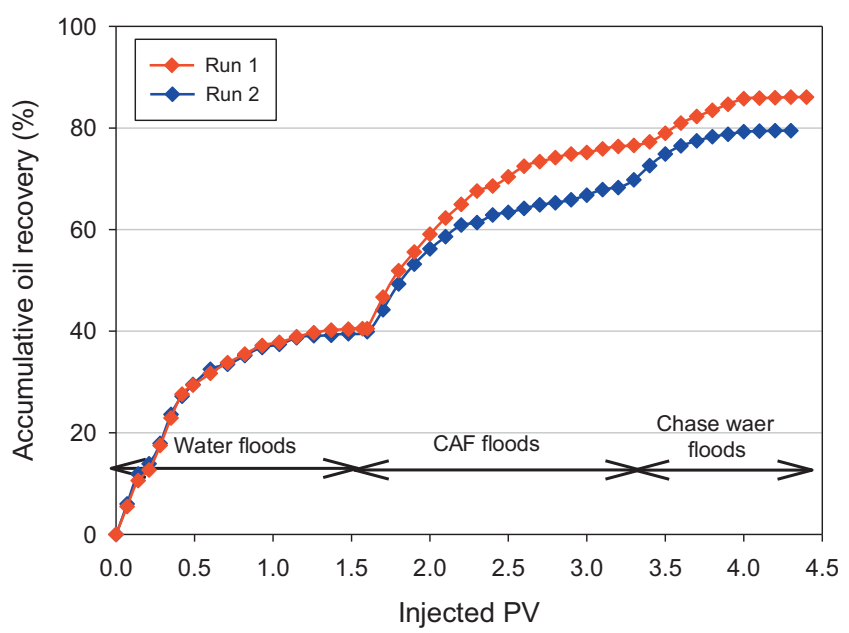

Figure 18

Effect of the injection sequence on the accumulative oil recovery of the CAF flooding.

\section{CONCLUSION}

In this contribution, a novel $\mathrm{CO}_{2}$-EOR method, named as Chemical-Alternating-Foam (CAF) floods has been developed and thoroughly assessed. One part of this paper compared the flowing behaviour of the continuous foam injection with that of the CAF floods in the porous medium. The two EOR methods applied the same amount gas and chemicals. The other part optimized the displacement performance of the proposed CAF floods. The main experimental observations include:

- Elevated temperature had negative impact on the RRF for both injection methods. However, CAF flooding was endowed with greater capability to reduce the brine permeability compared to the continuous foam flooding, which was validated the higher of the former;

- The overall oil recovery of the CAF flooding was $10 \%-15 \%$ higher compared to that of the conventional foam flooding with the same amount of $\mathrm{CO}_{2}$ and chemicals been injected. It appeared that the accumulative recovery reached the plateau when the total amount of supercritical $\mathrm{CO}_{2}$ and chemicals was greater than $1.8 \mathrm{PV}$;

- As for the continuous $\mathrm{CO}_{2}$ foam flooding, the best displacement performance was obtained at the $60 \%$ water cut, while the CAF floods yielded the most amount of incremental oil at the $98 \%$ water cut;

- Under the experimental condition, the optimal foam quality, foam/chemical slug size ratio and cycle number for the proposed CAF floods were selected as 80\%, 1:1 and 3 respectively. It was believed that the CAF flooding was able to display the extraordinary displacement behaviour under the optimal condition;

- The injection sequence of the foam and chemical indeed influenced the CAF flooding performance, but in a less noticeable magnitude compared to the other variables mentioned above.

\section{ACKNOWLEDGMENTS}

The authors wish to thank the financial support and technical assistance from Department of Petroleum Engineering at Curtin University. We are also thankful to Research Institute of Petroleum Exploration \& Development (Beijing) for providing polymer samples.

\section{REFERENCES}

Alvarez J.M., Rivas H.J., Rossen W.R. (2001) Unified model for steady-state foam behavior at high and low foam qualities, SPE J. 6, 3, 325-333.

Bernadiner M.G., Thompson K.E., Fogler H.S. (1992) Effect of foams used during carbonate acidizing, SPE Prod Eng. 7, 04, 350-356.

Casteel J.F., Djabbarah N.F. (1988) Sweep improvement in $\mathrm{CO}_{2}$ flooding by use of foaming agents, SPE Reserv. Eng. 3, 4, 1186-1192. 
Chen M., Yortsos Y.C., Rossen W.R. (2005) Insights on foam generation in porous media from pore-network studies, Colloids Surf. A 256, 2-3, 181-189.

Ebrahimi B., Mostaghimi P., Gholamian H., Sadeghy K. (2016) Viscous fingering in yield stress fluids: a numerical study, J. Eng. Math. 97, 01, 161-176.

Falcone J.S., Krumrine P.H., Schweiker G.C. (1982) The use of inorganic sacrificial agents in combination with surfactants in enhanced oil recovery, J. Am. Oil Chem. Soc. 59, 10, 826A-832A.

Fjelde I., Zuta J., Hauge I. (2009) Retention of $\mathrm{CO}_{2}$-foaming agents on chalk: effects of surfactant structure, temperature, and residual-oil saturation, SPE Reservoir Eval. Eng. 12, 03, 419-426.

Friedmann F., Chen W.H., Gauglitz P.A. (1991) Experimental and simulation study of high-temperature foam displacement in porous media, Soc. Pet. Eng. J. 6, 1, 37-45.

Gauglitz P.A., Friedmann F., Kam S.I., Rossen W.R. (2002) Foam generation in homogeneous porous media, Chem. Eng. Sci. 57, 19, 4037-4052.

Gogoi S.B. (2011) Adsorption-desorption of surfactant for enhanced oil recovery, Transport Porous Med. 90, 589-604.

Harris P.C. (1995) A comparison of mixed gas foams with $\mathrm{N}_{2}$ and $\mathrm{CO}_{2}$ foam fracturing fluids on a flow Loop viscometer, SPE Prod. Facil. 10, 03, 197-203.

Haugen A., Mani N., Svenningsen S., Brattekas B., Graue A., Ersland G., Ferno M.A. (2014) Miscible and immiscible foam injection for mobility control and EOR in fractured oil-wet carbonate rocks, Transport Porous Med. 104, 1, 109-131.

Jian G., Hou Q., Chen S., Wang D., Luo Y., Wang Z., Zhu Y. (2012) Comparative study of extensional viscoelasticity properties of liquid films and stability of bulk foams, J. Dispersion Sci. Technol. 34, 10, 1382-1391.

Jonas T.M., Chou S.I., Vasicek S.L. (1990) Evaluation of a $\mathrm{CO}_{2}$ foam field trial: Rangley Weber Sand Unit, 65th SPE-ATC, 23-26 September, New Orleans, LA.

Khatib Z.I., Hirasaki G.J., Falls A.H. (1988) Effects of capillary pressure on coalescence and phase mobilities in foams flowing through porous media, SPE Reserv. Eng. 3, 3, 919-926.
Kutay S.M., Schramm L.L. (2004) Structure/performance relation for surfactant and polymer stabilized foams in porous media, J. Can. Pet. Technol. 43, 19-28.

Le V.Q., Nguyen Q.P., Sanders A. (2008) A novel foam concept with $\mathrm{CO}_{2}$ dissolved surfactants, $\mathrm{SPE} / \mathrm{DOE}$ Symposium on Improved Oil Recovery, 20-23 April, Tulsa, OK.

Majidaie M., Khanifar A., Onur M., Tan I.M. (2012) A simulation study of chemically enhanced water altering gas (CWAG) injection, SPE EOR Conference at Oil and Gas West Asia, 16-18 April, Muscat, Oman.

Ozbayoglu M.E., Kuru E., Miska S., Takach N. (2002) A comparative study of hydraulic models for foam drilling, J. Can. Petrol. Technol. 41, 06, 52-61.

Prigiobbe V., Worthen A.J., Johnston K.P., Huh C., Bryant S.L. (2016) Transport of nanoparticle-stabilized $\mathrm{CO}_{2}$-foam in porous media, Transport Porous Med. 111, 01, 265-285.

Schramm L.L., Novosad J.J. (1990) Micro-visualization of foam interaction with a crude oil, Colloids Surf. 46, 1, 21-43.

Tay A., Oukhemanou F., Wartenbery N., Moreau P., Delbos A., Tabary R. (2015) Adsorption inhibitors: a new route to mitigate adsorption in chemical enhanced oil recovery, SPE Asia Pacific Enhanced Oil Recovery Conference, 11-13 August, Kuala.

Thorat R., Bruining H. (2016) Foam Flow Experiments. I. Estimation of the bubble generation-coalescence function, Transp. Porous Med. 112, 01, 53-76.

Wang J., Ge J., Zhang G., Ding B., Zhang L., Jin L. (2011) Low gas-liquid ratio foam flooding for conventional heavy oil, Petroleum Science 8, 3, 335-344.

Worthen A., Bryant S., Huh C., Johnston K.P. (2013) Carbon dioxide-in-water foams stabilized with nanoparticles and surfactant acting in synergy, AIChE J. 59, 9, 3490-3501.

Xu X., Saeedi A., Liu K. (2017) Experimental study on a novel foaming formula for $\mathrm{CO}_{2}$ foam flooding, J. Energy Resour. - ASME 139, 0229021-0229029.

Manuscript submitted in May 2016 Manuscript accepted in November 2016 Published online in January 2017

Cite this article as: X. Xu and A. Saeedi (2017). Evaluation and Optimization Study on a Hybrid EOR Technique Named as Chemical-Alternating-Foam Floods, Oil Gas Sci. Technol 72, 1. 